\title{
Should Aspergillus screening before bronchial thermoplasty?
}

\author{
Shinji Sasada* (1)
}

Keywords: Allergic bronchopulmonary Aspergillosis, Bronchial thermoplasty, Severe asthma

\section{Main text}

Thank you for your feedback. If there were any findings suspicious of allergic bronchopulmonary Aspergillosis (ABPA), aspergillus-specific antibody measurements and skin tests would have been performed as screening [1]. However, this case did not show any findings considered to be ABPA such as bronchodilation and mucus plugs on computed tomography (CT) and bronchoscopy before treatment [2]. On the other hand, regarding the sessions of bronchial thermoplasty (BT) for severe asthma, the third session was performed after the sample was collected, so BT treatment was completed. Regarding BT indications, although regular steroid administration was not performed in this case, a single rescue steroid administration was performed, and it is judged to be within the indication in Japan.

The question is, do you order Aspergillus-specific antibodies or skin tests on all cases of asthma that are not abnormal on $\mathrm{CT}$ and bronchoscopy?

\section{Abbreviations \\ ABPA: Allergic bronchopulmonary Aspergillosis; BT: Bronchial thermoplasty; $\mathrm{CT}$ : Computed tomography.}

\section{Authors' contributions}

S. S. significantly contributed to this paper.

\section{Funding}

No funding sources were used.

\section{Availability of data and materials}

All data and material are available for sharing if needed.

\section{Declarations}

Ethics approval and consent to participate

Not applicable.

\section{Consent to publish}

Not applicable.

\section{Competing interests}

The authors declare that they have no competing interests.

Received: 11 February 2021 Accepted: 11 May 2021

Published online: 09 June 2021

\section{References}

1. Asano K, Hebisawa A, Ishiguro T, et al. New clinical diagnostic criteria for allergic bronchopulmonary Aspergillosis/mycosis and its validation. J Allergy Clin Immunol. 2021;147:1261-1268.e5. https://doi.org/10.1016/j. jaci.2020.08.029.

2. Sasada S, Ohmura K, Oguri T, et al. A case report of Aspergillosis accompanied by saccular bronchodilation after bronchial thermoplasty in a 19-year-old woman. BMC Pulm Med. 2020;20:312. https://doi.org/10. 1186/s12890-020-01352y.

\section{Publisher's Note}

Springer Nature remains neutral with regard to jurisdictional claims in published maps and institutional affiliations. 